\title{
The Undergraduate Library of the
}

\section{University of Michigan}

$T_{1}$ HE CONFERENCE ON "The Place of the Library in a University" held at Harvard in 1949 honored more than the completion of a unique library building. The participants were celebrating a break with an outworn tradition which assigned a relatively low priority to undergraduate library service and relegated the younger student to second-class status in the library.

Throughout the later nineteenth and early twentieth centuries, while the great American universities were developing their graduate schools and striving for distinction as centers of advanced study, the highest priorities in their library programs had to be assigned quite naturally to the acquisition and organization of research collections and the service of recondite scholarship. Since the university is a community of scholars, the university library building itself had been conceived in terms of service to the higher order of scholarship and a reflection of the scholarly aspiration of the institution. Alumni interest may center more in the stadium and field house but the symbol of the university and a gauge of its distinction for the scholarly world always has been its research library, the "heart" of the institution as the wistful metaphor has it. The research library building, consequently, was designed well into the 1930 's (and in some instances into the ' 40 's) as both inspiring symbol and center of bibliographical research activity. It offered storage for great numbers of

Dr. Wagman is Director, University of Michigan Library. books, study cubicles for the faculty, and carrells and seminar rooms for the graduate students. It impressed visitors with an imposing lobby and appropriately sententious Latin inscriptions on the walls. Invariably it also contained a cathedral-like, dimly lit main reading room which housed a collection of reference works and was furnished with long tables and chairs in an arrangement favored by dormitory dining halls to achieve maximum utilization of seating space for brief periods of time. The use of the reference collection bore no relationship to the abundant space in which it was housed, consequently this room usually served as the main "study hall" of the library where the undergraduates might read books brought to them from the stacks, or more often, study their own textbooks and lecture notes. The reference department was often housed in this room and it was mistakenly assumed that the reference staff would be able, because of proximity, to steal enough time from the work of clipping newspapers, organizing vertical files, handling interlibrary loans, and performing difficult bibliographical chores for the faculty and graduate students, to assist the undergraduates adequately with their minor bibliographical problems. The stacks were closed to undergraduates because the scholarly volumes had to be protected and also because no library could afford the shelf-reading entailed in granting thousands of inexperienced students free access to all the books. Special rooms were often provided also for rare books or special collections, and for periodicals. 
This basic pattern was modified by the addition of reserve-book reading rooms or service points and by additional study halls, frequently in other buildings and usually staffed by student assistants or clerical employees. As the universities grew and branch libraries were spawned, the gross addition of seating space available for study or reading seemed to solve the problem of undergraduate library needs, but only because on one hand the students' inexperience prevented them from perceiving and articulating their needs, and on the other because the tacitly accepted philosophy of undergraduate education did not illuminate them. Frequently librarians with strong humanistic leanings established browsing collections or poetry rooms. Occasionally, also, an effort was made to establish an undergraduate library within a room of the main library building with a collection of good books and periodicals, and with some reference or readers' advisory service. Some of these innovations were noteworthy but not all succeeded.

This picture is over simplified and exaggerated, of course. The introduction of the modular building, the divisional arrangement of collections, and acceptance of the principle of easy accessibility of the collections have effected great changes in library planning and architecture in the past two decades, especially in the case of smaller university library and college library buildings. But the largest university libraries are fixed architecturally in the old pattern and can overcome the limitations of their design only in scattered cases. Despite their huge undergraduate enrollments the libraries of many of these very large universities could not have been better conceived or designed to discourage use by young students. Their book collections are relatively inaccessible. Too few copies of the best and most needed books can be made available. The staff of reference librarians is too limited and harassed to be very helpful. The rooms assigned to undergraduate students are frequently depressing. The catalog is too large and complicated. In few of these institutions is there a carefully planned program in force that will help the student acquire facility in working with the bibliographical tools essential for the intelligent use of the human record.

The peculiar inadequacy of library facilities for undergraduate use, furthermore, has affected seriously the nature of undergraduate teaching at such institutions. The faculty has had to rely on the lecture and textbook method in too many instances because the use of source and secondary materials in the library is so difficult. It has become fashionable to decry the lecture course and the use of textbooks in other than basic science and language study and this too is an error which overlooks the inspiration that the good teacher can offer in his lectures and the economy of importing factual information quickly in condensed and organized form through the textbook. There is no question, however, that in far too many cases, the use of textbooks and formal lectures to large non-participating student audiences has failed to further the educational aim of developing in the students a zeal for intellectual inquiry and a lifetime interest in reading the best thought and creative product of both the past and the current period. Unfortunately, moreover, some of our faculty members mistake painful necessity for virtue and tend to suspect any serious effort to break with the lecture-and-textbook tradition as boondoggling based on a romantic misconception of the nature and interests of the undergraduate student.

It is probably a moot point whether instructional practice governed the pattern of library service, or vice versa, and it may well be argued that both were cause and both were effect. At any rate, the librarians are not to be blamed for 
the rather sad state of library service to undergraduates at some of these larger universities. They are the product of their institutions, or of similar universities. They work in organizations which are hierarchical and aristocratic in nature, where emphasis has always been placed on service to the privileged group, the faculty and graduate students. Almost never are they given budgets which would permit them to carry out a program based on a broad view of the library potential for service. Finally, although Harvard's pioneering in this field offers startling exception to John K. Galbraith's thesis, commonly accepted ideas are usually altered by circumstances rather than by other ideas, and it is difficult to persuade some teachers who wrote their lecture notes many years ago and re-edited their anthologies or textbooks recently, that it would be beneficial if they took the time necessary to revamp their courses completely and expose their students to a great many published sources. It is difficult furthermore to persuade some faculty members that the library might serve education better if it provided a few more copies of a book useful to undergraduates at the sacrifice of recondite items relating to their research. The latter choice should not be necessary, of course, and ideally neither librarian nor professor should be compelled to make it. To avoid this necessity, however, the library budget would have to be shaped by a different attitude toward the library's role in undergraduate education on the part of university administrators and sympathetic understanding would be needed in the state legislatures.

It is a tribute to Harvard that it was the first among the great universities to attack this situation and that it did so, not under the pressure of increased enrollment, not because circumstances forced it, but because it wished to improve library service to undergraduates despite the increasing demands of schol- arship. It should be remembered that at Harvard the graduate students outnumber the undergraduates and that the Widener Library and the many branch libraries offer far more by way of library facilities than is available at most universities to serve much larger student bodies. Additionally, Harvard had already developed a system of house libraries for the benefit of its undergraduates. Nevertheless, in his address at the conference referred to above, Keyes Metcalf stated as the first premise on which the Lamont Library was planned: "The undergraduates will make more and better use of a library designed expressly for them." Mr. Metcalf did not leave this statement exposed and unsupported by practical considerations. He went on to list as additional premises: "That this was the best way to relieve the pressure in the Widener building and make unnecessary a new central building; and that if the pressure were relieved, the Widener Library building would become a more satisfactory research center than it has been in the past." 1 All three of his premises were correct. It is to his credit that he listed them in their proper order of importance.

Donald Coney, speaking after $\mathrm{Mr}$. Metcalf, expressed a view that very probably was shared by the other librarians of state universities at the conference. He estimated that the cost of a Lamont Library for the Berkeley campus would be at least $\$ 4,250,000$. "A Lamont Library," he went on, "can be realized on state university campuses only if administrators and librarians are skillful in presenting the library needs of the state's youth so persuasively that legislatures will see the light. ... More important than this act of persuasion, however, is a decision which must be taken earlier, and by librarians and university administrators. I mean the decision that, im-

1 The Place of the Library in a University, $A$ Conference Held at Harvard University 30-31 March, 1949 (Cambridge: Harvard University Library, 1950), p. 42. 
portant as it is to have libraries for books, it is also important to have libraries for people."2

Mr. Coney's statement of requirements was also quite correct and it seemed, at the time, that he was posing insuperable conditions. It was all very well for Harvard to build the Lamont Library. Harvard already possessed the vast collections of Widener. It had built its Houghton Library. It had only about forty-four hundred undergraduates. But how could the state university libraries with inadequate book budgets, with library buildings inferior to Widener, and with several times as many undergraduates as Harvard hope to follow this example? Would it be wise for them even to try? Today, an undergraduate library similar to the Lamont in conception has been in use for a year at the University of Michigan and at least six other large universities are busily planning or are seriously considering construction of such libraries designed for undergraduate "people."

Much has happened in the past ten years to weaken the influence of the traditional view. The example of the Lamont Library has had a great effect on librarians and on numerous university administrators, but even more important has been the pressure of constantly and rapidly increasing enrollments and the promise (or threat) of further tremendous increases in enrollment by 1963 . There is no less need for continuing attention to the development of research collections today. Indeed, the increase in graduate enrollments is dramatic and the emergence of new disciplines, the increase in research publication in relatively new fields of knowledge has complicated the lives of research librarians enormously. At the same time it has become apparent to all who are not completely in thrall to traditional concepts that the old library expedients simply will not suffice to accommodate the growing influx of undergraduate students.

2 Ibid, p. 55.
Several decades ago the university librarian might have solved his problem of overcrowding by opening two or three convenient study halls in strategically located buildings or in his main library building. The prospect of providing such scattered rooms for fifteen to twenty thousand undergraduate students and of duplicating even minimal reserve reading and reference collections in the number of study halls that would be required seems absurd. Our predecessors might have cherished the hope that increasing undergraduate need for library service might be solved by a system of "house libraries" similar to Harvard's. The Harvard decision that its "house libraries" alone were not adequate for four to five thousand students raised doubts as to the efficacy of this solution. Moreover, a proposal to provide truly adequate libraries in a dozen huge dormitories, without making any provision at all for the thousands of students who reside in fraternities, sororities, cooperative housing, apartments, and rooming houses, can hardly be considered.

Once these theoretical solutions are rejected as inadequate per se it is easier to rethink the question of where and how the undergraduate should be served by the library. Other factors have contributed to make such reconsideration feasible and even necessary. For one, it has become apparent to any observant person on a university campus today that the conventional, negativistic attitude which argues with automatic responses against a real library program for undergraduates is unrelated to reality. The tired theses that undergraduate students are uninterested in good reading; that they are too "overorganized"; that their course work, extra-curricular activities, and social life would prevent their taking advantage of a good library are ridiculous rationalizations, at best, of our failure to provide the younger students with equal library facilities. 
Another contributing factor has been the threat from a new quarter to the conventional and economical pattern of undergraduate instruction. For if the lecture-and-text-book system of instruction (with a little required outside reading thrown in) is the best way to teach so many college courses, then modern electronics should make it possible to achieve even greater economies and make maximum use of the most talented and inspiring lecturers. The recent closedcircuit-TV scare seems to have abated on university campuses, despite the fact that experimentation with television in teaching continues. Meanwhile, however, many university teachers have felt compelled to re-examine their pedagogical method. Snide remarks about Professor Loverboy on the screen of the idiot-lantern were expressive of faculty resentment against the fond hope that television offered a panacea for the problem of undergraduate instruction, but they failed to erase the sudden concern about the need for other, more flexible instructional methods. Interest seems to be growing in the possibility of including not only honors students but many others in courses that require minimal faculty supervision and leave the student free to work on his own with the source materials and commentaries in the Iibrary. Even if there is to be no important development of such reading programs at our universities, many professors and deans have considered, and are considering, the possibility of using the library more and in new ways in the instructional program, and this also is preparing the proper climate for acceptance of the idea of the undergraduate library.

Finally, and far from least, undergraduate education suddenly assumed new and dramatic importance when a canine heart beat was transmitted from outer space under Russian auspices. Although the new hue and cry for more and better instruction seems to relate primarily to mathematics, the sciences, and technology, the general effect has been to draw more attention to education at the college level than it has ever enjoyed. The university undergraduate can no longer be regarded or treated as a second-class citizen. The present trend is almost certain to encourage development of new library facilities for undergraduates if it is argued cogently that they will help equip him for his crucial role in this new era of national danger.

As has been indicated, the idea of the undergraduate library is not new, nor was it new in 1949 when the Lamont Library was completed. It has come to mean a great deal more, however, than the words themselves connoted a short time ago, just as the term "modular building" means much more to the contemporary librarian than a structure built to a module of fixed or standard size. Essentially it signifies an effort to correct certain library errors of the past vis $a$ vis the undergraduate student. It means a library designed entirely, and only, with the needs of the undergraduate in mind, on the premises that the library should be as important as the teacher in undergraduate education, and that any undergraduate may realize his potentiality of developing a life-long interest in reading good books and in continued self-education if the library assists him and makes the process attractive. It means not merely a library but a cultural center for the undergraduate student on the huge university campus and a focus for his intellectual activity while he is in residence there.

In 1952 the University of Michigan set aside a plan, developed over about a decade, for the enlargement of its general library building. The remodeling and expansion of this building, at very high cost, would have improved it greatly for use by the graduate students and faculty but would not have provided for undergraduate needs to any significant extent. 
A substitute program was drawn up calling for some remodeling of the General Library; for construction of a library storage building and bindery; and for a separate undergraduate library building.

The program written subsequently for this undergraduate library stated, as basic principles, that everything possible should be done in the architectual planning and in the selection of books and staff to make the library inviting and easy to use; to give the students the impression that the librarians were employed to assist rather than supervise or monitor them; and to help the undergraduates develop a proprietary interest in their library. To insure maximum flexibility of the space provided, a modular building was called for. The rectangular form and orientation of the only site available governed the shape of the building and even its external appearance. The desire to avoid producing a structure that would be offensive in appearance between the buildings on either side and the limitation on the appropriated funds available for the construction governed the number of floors that could be provided above and below grade respectively. Accommodation of the plan to the various strictures resulted in a structure $240 \times 120$ feet, built on a module $30 \times$ 24 feet, with four stories above grade and one below. The building contains 145,000 square feet, most of it in the form of a large undifferentiated area on each of the four lower floors which can be adapted for almost any conceivable use. Lighting, air conditioning, and liberal provision of electric and telephone outlets will make possible the erection of partitions in almost any pattern desired in the future.

It was decided early in the planning that the entire book collection would be placed on open shelves. To facilitate the finding of books, the floor plan was simplified to the ultimate degree and no sacrifice of this simplicity was subsequent- ly permitted for the sake of architectural effect. Critical examination of the reasons usually advanced for keeping reserve books behind a barrier led to the conclusion that it would be feasible, although more costly, to place the reserves where they belong in the classification system, on the open shelves, provided one marked them with a distinctive symbol and controlled the exits from the building. Exception to this rule has been made only for occasional items such as reprints of journal articles lent to the library by the faculty for class use. The planning committee decided also that the only argument against allowing the students to smoke anywhere in the airconditioned building was the janitorial cost of emptying ash trays at night and that this argument was not compelling. Similarly, it seemed foolish to make students who were spending long hours in the library leave the building in order to get a cup of coffee, so a coffee shop was provided even though this meant extra floor washing in one room.

Since the ideal of complete privacy, a separate room for every reader, is unattainable, a compromise was effected. The large reading area on every floor is broken by a row of group study rooms along one wall, each of which can accommodate eight students, by the ranges of book shelving and by placement of colorful "space-breakers" or screens. As a result one is not given the sensation of sitting in a very large room in any reading area. One-third of the seating provided is at individual tables attached to the screens or along the walls. The rest of the seating is at tables designed for four students, except that the arrangement of tables is interrupted by occasional groupings of lounge furniture. Despite the disproportionate ratio of seating to book space, the reader is conscious of the proximity of the books in all parts of the reading areas.

All tables were designed to offer each 
reader $3 \times 2$ feet of work surface. The chairs were designed to provide maximum comfort over long periods of time and yet to serve as an important ingredient of the decorative scheme through their colored upholstery. Careful selection of flooring material, ceiling construction, and lighting has resulted in glare-free even illumination and an extremely low noise level. The grouping of special purpose rooms at one end has simplified the traffic patterns and provides maximum flexibility of space in the reading areas. Decoration was achieved through the use of color in the upholstery, on the "space breakers," and on the rear wall of each room. The total effect is one of lightness and of pleasant, colorful, informality. Despite the constant stream of students in and out of all parts of the building there is little impression of confusion.

It was agreed that the book collection should represent the best in the human record of the past and in current thought. With the aid of hundreds of faculty members and a process of book selection that went on for more than two years, an initial stock of $60,000 \mathrm{vol}$ umes and 150 periodical titles was assembled and cataloged. Important omissions from this collection are being corrected currently and it is the intention to keep the collection current by the addition of new books that contribute to knowledge. Inasmuch as the entire collection is a browsing collection, in effect, no separate browsing collection was provided and no special "recreational" reading collection, based on the notion that "recreational" is synonymous with "second-rate" or even with "meretricious."

The faculty members were asked to rethink their courses and submit new required or recommended reading lists. An attempt was made to procure one copy of each of these titles for every twelve or thirteen students enrolled in the respective course. In addition a substantial collection of reference books was placed on the open shelves where they are accessible to both staff and students. It has been found necessary to augment the reference collection rapidly. The problem of helping a student halfway to an answer and then referring him to the General Library for additional assistance becomes intolerable in practice if not in theory.

Books and periodicals are not the only library materials undergraduates need or should be exposed to, and a special room was provided for listening to recorded music, poetry, and drama. Equipped with 151 seats, 72 turntables, at each of which two students may listen with earphones, 7 cubicles for listening to loudspeakers, and a control room from which programs may be played over 13 channels by record or tape and tuned in at each of the seats, this facility provides library support for the popular courses in music literature which enroll hundreds of students each year. A multipurpose room equipped with 200 stacking chairs, motion picture projectors, and public address system is used by the students for lectures, discussion groups, motion pictures, or for any affair which concerns undergraduates and the library. Additionally, one room was equipped with four motion picture projectors on which several students may view different documentary films simultaneously, listening to the sound through headphones, or where a small class may watch a documentary film. On the main floor of the library an exhibit area was provided where the Fine Arts Museum staff arranges small monthly shows of prints, most of them brought to Ann Arbor on loan. On the top floor a large display room was made available to the fine arts department. Equipped with museum benches and tackboard on the walls and on several large screens, it offers an ideal space for five hundred 
students to study the prints and photographic reproductions with which they must familiarize themselves for their fine arts courses.

For a few years, until a new classroom and library building can be provided on the University's new north campus for the School of Engineering, the library of that school is being housed on the third floor of the Undergraduate Library. Similarly, the Transportation Library is being housed temporarily on the fourth floor.

The Undergraduate Library was opened on January 18, 1958. The response of the students was overwhelming and a dramatic revelation of past inadequacies. Prior to this date there had been available for the use of the undergraduates, apart from the main reading room in the General Library and the numerous branch libraries, three reading rooms seating 489 students in crowded fashion, housing negligible collections of books, and staffed by library science students or other student assistants. The new building seats 2,200 very comfortably and is staffed with ten professional librarians who provided reference aid and supervise a large staff of clerical and student assistants. Both building and staff have proved to be much too small.

In the first year of operation, the library counted 1,420,865 users. More than 9,500 students have used the library on one day and on many days the number ranges between 8,500 and 9,000. It should not be suspected that the volume of "visitors" bears no relation to use of the collection. During this first year the Undergraduate Library circulated 134,719 volumes for home use. A total of 280,037 volumes were used in the building and had to be reshelved by the staff. How many additional volumes were used and properly reshelved by the students themselves cannot be determined. In short, at least six and one-half times as many volumes were used or borrowed by the students as the collection contains.
Meanwhile, circulation in the branch libraries and in the General Library has not declined. Home circulation from the Undergraduate Library and General Library combined exceeded the total home circulation from the General Library alone for the corresponding period in the previous year by more than 135 per cent. Analysis of the circulation for home use indicated that 37.7 per cent represented voluntary reading and 62.3 per cent was course-related. Further analysis of the course-related reading reveals that a very large part of this also was not required but apparently was stimulated by the course work.

The statistics quoted above reflects use of the new library in its infancy and before a considerable part of the faculty had begun considering its potentialities as an aid to their teaching. The rate of both building and book use has been climbing steadily and threatens to be phenomenally high this spring. Many students have already adopted the practice of arriving at 6 p.m. to insure that they will have a seat available for the evening. On numerous evenings in recent weeks students have been observed sitting on the stairs and floors to read, because the chairs were all occupied.

Other less measurable effects of the new library are noteworthy. It has definitely become the hub of undergraduate activity on the campus. Its central location has made it possible for the students to spend the hours between classes reading in the library and thousands of them do so. Many students are now using the library who confess that hitherto they had preferred the movies to the study halls and had rarely or never ventured into the General Library. Obviously, also, the undergraduates are reading a great many more good books than before and under the guidance of the reference staff, short-handed as it is, are learning how to use a library catalog, indexes, bibliographies, and other reference works. Psychologically, the effect of this 
library on the students has been extremely gratifying. Formally, through the spokesmen for their organizations, they have, of course, indicated their appreciation of this new facility but, more important, many of them individually have made it a point to tell the staff that the new library has made a tremendous difference in their daily lives. Moreover, the success of the Undergraduate Library has stimulated the students to plan the development of small libraries in the dormitories which they will administer themselves. A committee is at work enthusiastically on plans for a series of such house libraries.

It had been feared that free access to the reserve books would result in their rapid disappearance and, in fact, one per cent of the total book stock did disappear in the spring semester last year. As a result, the Regents of the University approved a new regulation that any student who mutilated a book or removed it from the building without charging it would be fined $\$ 100$ or would be suspended. The penalty has been imposed twice this semester and indications are that book losses have decreased. At the same time, the fine for late return of books was increased sufficiently to make it painful and late returns have also decreased. Both new regulations were endorsed by the students, most of whom seem to resent the theft of needed books from their library even more, perhaps, than do the librarians. Also, contrary to the fears of some that the permissive attitude as regards smoking, the provision of a coffee shop and the absence of supervision would lead to mistreatment of the furniture, books, and the building itself, there has been no damage as a result of student neglect or indifference and there seems to be no reason to fear that the students' proprietary interest in the library will not continue. Finally, the fear that the library would serve primarily as a social club, an ideal place to meet one's date or make new friends, especially in the winter months, has proved to be needless. Of course, students do meet in the library and the "study date" continues to be a popular custom, but this is an earnest generation. The first group of students admitted to the library on the day it opened included an astonishing number who went directly to the bookshelves or catalog without even taking time to tour the building. They typify the undergraduate today better than the image most of us have carried in our minds since our own undergraduate days. Moreover, in these times, at a university which provides almost thirteen hundred apartments on its campus for married students, the boy and girl holding hands while they read Gesell and Ilg may well be husband and wife preparing simultaneously for their next class and for a future, predictable "act of God."

The effect of the new library on the faculty has been equally interesting. While the building was under construction a very considerable number of professors understood its potential value and were eager to have it completed. There were a few others, however, who were convinced that the project was a wasteful diversion of funds which might better be used for other library purposes. On several occasions, members of the library staff found it necessary to meet with apprehensive faculty groups and reassure them that the book collection would not represent transfers, for the most part, from the research collections and that if any such transfers were to be made, the departments most concerned would be consulted beforehand.

It is apparent now to all that the percentage of extra copies in the new collection is not so heavy and that the book collection of the undergraduate library is a welcome addition. Over and over again it became apparent that copies of notable books purchased for the new collection were not really additional at all; the older copies recorded in the 
General Library catalog all too often had been lost, stolen, or worn out. More important, however, an increasing number of members of the faculty (including professors in the sciences) are "teaching with books." Courses represented by reading lists in the library increased onethird this fall as compared with the preceding spring semester and faculty interest in using the library as an aid to their teaching has begun to exceed the library's ability to keep up. This past fall, the University of Michigan was compelled to work with a reduced budget. It was not possible to staff the undergraduate library without reducing services in, and book funds for, the General Library and the branches which serve the faculty and graduate students. Regrettable though this was to all concerned, there was no resentment over the sacrifice. Indeed numerous professors have assured the library staff that the new library simply must be well supported, and almost every week members of the faculty propose additional services for their students which would require that the new facility be given an even larger share of the library budget.

The effect of the new building on the General Library and the branch libraries has been as anticipated. These are now used predominantly by graduate students and faculty. The stacks of the General Library have been opened to all and it also is now, for the most part, an openshelf library. Graduate students have been working in the General Library and the branches in much greater number than ever before and it has become possible to adapt much of the space formerly pre-empted for undergraduate reading rooms to special uses. The reference department and the branch librarians have more time to spend on service to faculty and graduate students and on bibliographic enterprises. It has been possible to curtail the staff of the circulation department in the General Library despite the fact that circulation of books from that collection has not decreased.

The value of the Michigan Undergraduate Library as an example is not to be sought primarily in its solution to the various specific problems of architecture or librarianship. Errors were made in both respects, of course, that will be avoided in newer libraries and a number of problems have not yet been perfectly solved. Nor should it be assumed because it is proving to be successful on one campus that an identical library is needed or would be justified at all other large universities. Its importance lies in its clear demonstration of the fact that a greater investment in library service to undergraduate students on the very large university campus will elicit a dramatic response from the students in terms of their attitude toward course work and toward the process of education generally and an equally gratifying response from the faculty in terms of their teaching with books. It offers a warning also. The cost of the building, books, and staff is far higher than experience would allow one to estimate on any campus where frustration of undergraduate students in their effort to use the library has been a condition of many years -standing. A building that contains 145,000 square feet and cost $\$ 3,105,000$, an initial book collection that cost $\$ 200,000$ and approximately the same amount again to acquire and catalog, a very heavy investment of staff and faculty time in planning and book selection, and a budget of $\$ 138,000$ per year for staff (apart from janitorial and maintenance costs) are not adequate to satisfy the need at the University of Michigan. The potentialities for service are only gradually being realized by the Michigan librarians and faculty in this very early stage of the new library's existence and the annual cost of operation is almost certain to increase steadily as both students and faculty discover increasingly how helpful the new library can be. 